\title{
Erratum to: Biological evaluation of antibody-maytansinoid conjugates as a strategy of RON targeted drug delivery for treatment of non-small cell lung cancer
}

Liang Feng ${ }^{1,2+}$, Hang-Ping Yao ${ }^{1,2+}$, Sharad Sharma ${ }^{2}$, Yong-Qing Zhou ${ }^{3}$, Jianwei Zhou ${ }^{4}$, Ruiwen Zhang ${ }^{5}$ and Ming-Hai Wang ${ }^{1,2^{*}}$

\section{Erratum}

Unfortunately, the original version of this article [1] contained an error. The name of one of the authors, Sharad Sharma, was not included in the author list.

The correct author list and the new "Authors' contributions" section have been correctly included in full in this erratum and updated in the original article.

\begin{abstract}
Authors' contributions
LF and HPY contribute equally to this work. LF was involved in preparation of antibody-drug conjugation, some in vitro and in vivo studies related to NSCLC. SS was involved in antibody characterization, some in vitro studies related to breast cancer. HPY and YQZ produced and purified anti-RON antibody, participated in some in vitro experiment, analyzed data, and provided partial funds for this project. JWZ provided experimental design and technical support for some intro experiments. RWZ participated in experimental design for combination study. MHW designed the study, participated in data analysis, wrote the manuscript, and secured the fund for completion of this study. All authors read and approved the final manuscript.
\end{abstract}

\section{Author details}

'State Key Laboratory for Diagnosis \& Treatment of Infectious Diseases and Collaborative Innovation Center for Diagnosis \& Treatment of Infectious Diseases, First Hospital of Zhejiang University School of Medicine, Zhejiang, China. ${ }^{2}$ Department of Biomedical Sciences, Texas Tech University Health Sciences Center School of Pharmacy, 1406 Coulter Street, Suite 1117, Amarillo, TX 79106, USA. ${ }^{3}$ Department of Neurosurgery, First Hospital of Zhejiang University School of Medicine, Zhejiang, China. ${ }^{4}$ Department of Molecular Cell Biology \& Toxicology, Nanjing Medical University School of Public Health, Jiangsu, China. ${ }^{5}$ Department of Pharmaceutical Sciences, Texas Tech University Health Sciences Center School of Pharmacy, Amarillo, TX, USA.

Received: 25 May 2016 Accepted: 25 May 2016

Published online: 17 June 2016

\footnotetext{
* Correspondence: minghai.wang@ttuhsc.edu

${ }^{\dagger}$ Equal contributors

'State Key Laboratory for Diagnosis \& Treatment of Infectious Diseases and Collaborative Innovation Center for Diagnosis \& Treatment of Infectious Diseases, First Hospital of Zhejiang University School of Medicine, Zhejiang, China

${ }^{2}$ Department of Biomedical Sciences, Texas Tech University Health Sciences Center School of Pharmacy, 1406 Coulter Street, Suite 1117, Amarillo, TX 79106, USA
}

Submit your next manuscript to BioMed Central and we will help you at every step:

- We accept pre-submission inquiries

- We provide round the clock customer support

- Convenient online submission

- Inclusion in PubMed and all major indexing services

- Maximum visibility for your research

Submit your manuscript at www.biomedcentral.com/submit

valion of antibody-maytansinoid conjugates as a strategy of RON

targeted drug delivery for treatment of non-small cell lung cancer. J Exp

References 